\title{
Commentaries
}

\section{Wider "causal thinking in the health sciences"}

Mervyn Susser offers us in this issue ${ }^{1}$ another $^{2}$ timely warning about the future of epidemiology. An expression of the same concerns was echoed by the British Medical Research Council recently in its consultation about the future strategy for funding epidemiology. Put at its simplest these concerns arise firstly from the past successes of the methodology of epidemiology in determining vital causal relations from a quagmire of artefact and delusion; ever present in observing human health and health improvement. Secondly, that such approaches seem to have gone about as far as they can; with some important exceptions.

Despite its sophistication and obsession with sheer methodological rigour, epidemiology always appears a blunt tool, relative to laboratory medicine for example, but none the less has had an enormous amount to offer. The unique importance of epidemiology is, as Susser says, elucidating the problems of causal relations in health from actual observation of important and complex processes where the precise mechanisms are often poorly understood; from exposure to disease and from intervention to improvement. That is its obsession. And "risk factor" epidemiology remains an essential insight into the full nature and potential of improving human health, but it is clearly not sufficient.

The pressure is on and the question for epidemiology is how can it deal with the reality that "productivity declines; and young minds go elsewhere". What in fact is to become of epidemiology? I hope we will see the important development of ecoepidemiology, as Susser suggests, because that is one vital part of the epidemiological paradigm-but there are others too. The serious study of health in populations in all its manifestations certainly demands "technical capabilities and analytical tools beyond the present day resources of epidemiology". What is indeed required is a systematic development of the appropriate theoretical basis for public health - which is epidemiology - embracing the entire causative chain for better health.

It is worth looking at the professional development of epidemiology as well as the scientific and medical history. Jerry Morris asserted epidemiology as the core discipline in public health, ${ }^{3}$ as indeed it is. To understand and be a specialist in public health requires knowledge about the effective and efficient prevention of avoidable ill health, in all its manifestations. This certainly requires knowledge about risk factor epidemiology, but increasingly it requires knowledge about evidence in health on the determinants of risk, and health enhancing factors, be they social, biological, ecological, economic or political.

Yet to be a specialist in public health a crafty confidence trick has been perpetuated on the health of this nation, and others too, apparently in the name of standards and of effectiveness. Institutional public health in the UK today is a closed shop and it has marginalised epidemiology as core, without adequate reference to the really appropriate skills and competencies. ${ }^{4}$ Assuming (without evidence) that clinical medicine should be dominant, public health is now essentially (and inevitably) health service management. ${ }^{5}$

Simultaneously the strangest state of affairs has existed during my professional life in which students of postgraduate courses in epidemiology had to be medically qualified and yet taught by specialists of other disciplines. But, for the above reasons, the training of doctors in specialist epidemiology was simultaneously disparaged by public health, while management was given a greater importance. All other core intellectual disciplines have had to accept a purely supportive role to public health.

That is a sure way to guarantee the premature demise of a vital intellectual enterprise; subordinate it to the parochial career aspirations of a few and ignore the development of the true theoretical underpinning. The essential paradigm has suffered for too long under these ridiculous constraints.

Geoffrey Rose drew our attention a while $\mathrm{ago}^{6}$ to the "prevention paradox"-which roughly stated says that preventive interventions only benefit a minority of the "beneficiaries" directly and those who benefit are not necessarily individually identifiable. But this is not a paradox at all, but is clearly an anathema to the clinical method, directed at specific individuals benefiting from clinical interventions. All of public health is like that, and thus all of public health simply cannot be embraced by the individual risk factor model and its commensurate clinical emphasis.

Rose gave an enormous amount to public health but what he also gave was a high class MSc course in epidemiology open, until very recently, only to medically trained people. And that way the false notion of a paradox and the simplified health belief model remained dominant and constrained the theoretical basis for public health. We became very good at analytical studies identifying, without bias, the risk factors for this and that - all essential stuffbut the policy implications gradually became more and more obscure, under that model. That was because "behaviour" was not accorded the importance it deserves in the underlying analysis of appropriate public health strategy.

Without an adequate theory exclusive professions still need quick "solutions", hence embracing management takes on a particular attraction, in this case, of health services especially. Thus other core disciplines, had perforce to remain marginal and merely supportive and many "young minds" did (and continue to) go elsewhere because the professional barriers were simply too high. Once one discipline becomes dominant it will certainly fail to perceive the need for change. But the time, Susser tells us it seems, has now at last finally arrived.

The focus on risk factors ignores the true complexity of the behavioural effects and disparages important health promoting factors. The concentration on individuals overlooks social and structural group specific influenceswhich are actually often dominant. People never do important things ignoring their own overwhelming context. The dominant theoretical developments in epidemiology have effectively ignored the true dialectic that exists between people's actual chances and their real possibility of making choices. This is palpably not an entirely individual business because both the realities and the possibilities are determined by status and context, themselves in turn variously real and perceived. Style, as Weber tells us, ${ }^{7}$ is indeed important.

So the true paradox in epidemiology is quite profound. It is high time that public health stopped behaving as if one 
single dominant paradigm was good enough. It is not, and the theoretical basis for public health is overdue for a constructive reformulation and enhancement of epidemiology. Let us make absolutely sure that the intellectual basis is never again constrained by professional straight jackets to sort out any single group's special career aspirations - it is far too important for that. Susser is offering us one clear opportunity, among several, to improve the health of our communities, taking in the true nature of those communities. These must imply both multi-disciplinarity, but also greater methodological pluralism, where the synergistic opportunities for intellectual development are, in principle, immense. Contemporary public health must nurture and exploit them. ${ }^{8}$
Cancer and Public Health Unit, Department of Epidemiology and Population Health, London School of Hygiene and Tropical Medicine, Keppel Street, London WC1E 7HT

1 Susser M. Does risk factor epidemiology put epidemiology at risk? Peering into the future. $\mathcal{F}$ Epidemiol Community Health 1998;52:608-11.

Susser M, Causal thinking in the health sciences: concepts and strategies in epidemiology. New York: Oxford, 1973.

3 Morris JN. Uses of epidemiology. 3rd ed. London: Churchill Livingstone, 1975.

4 McPherson K, Fox J. Public health: an organised multi-disciplinary effort. In: Scally G, ed. Progress in public health. London: Royal Society of Medicine, 1997: 269-91.

5 Powles J, Day NE, McPherson K, et al. National Centre for public health is needed. [Letter]. BMF 1997;315:54.

6 Rose G. The strategy of preventive medicine. Oxford: OUP, 1992.

6 Rose G. The strategy of preventive medicine. Oxford: OUP, 1992 . Weber M. Essays in sociology. Gerthedge and Keegan Paul, 1958.
Routledgen

8 Chief Medical Officer's Project to Strengthen the Public Health Function in England. A report of emerging findings. London: Department of Health, 1998 
rejects the underlying assumptions of biomedical individualism." 3

Like microepidemiology, macroepidemiology is narrow; they are specialties. Anyone who would offer either of them, or risk factor epidemiology, as a paradigm for epidemiology itself would deserve McKinlay's charge that "socioeconomic reductionism among social scientists is as destructively myopic as biophysiologic reductionism among natural scientists." ${ }^{17}$ Susser's ecoepidemiology, in contrast, is breathtaking in the sweep of its scope. It encompasses the micro, the individual, and the macro levels. It is an epidemiology in which we can all get along. If the war of the epidemiologies continues, we fervently hope that Susser's ecumenical viewpoint will prevail. An ever widening schism between the extremes of social and molecular epidemiology cannot be productive. There should be a place in the epidemiological enterprise for all who seek to advance the cause of public health, including those who study societal influences, risk factors, and biochemical mechanisms.

Even if Susser's general vision holds sway and the discussion does take the optimistic and conciliatory turn we hope it does, plenty of room will be left for debate and disagreement. For example, does the study of ecological variables oblige us to conduct ecological analyses? Does ecological analysis successfully accommodate dependence of disease among individuals? What will happen when those who decry analytic complexity and who call for multilevel analysis find that the latter is intrinsically complex? If we were to study all levels "simultaneously," would our investigations become too unwieldy? If we were to study the levels "in sequence," would studies at levels far removed from disease occurrence (for example, studies of the effects of passing laws on levels of exposure to environmental chemicals) be appropriately called "epidemiology"? However interesting such questions may be, they are mere details in the wider debate. Susser's ecoepidemiology - a tent of broad enough expanse to cover the micro, the individual, and the macro levels-comes as a refreshing alternative to those who would claim that theirs is the only type of epidemiology worthy of the name.

The authors wish to thank Robert Millikan and Aaron Cohen for constructive criticism.

CHARLES POOLE

Department of Epidemiology (CB \# 7400), University of North Carolina School of Public Health, Chapel Hill, NC 27599-7400 USA

KENNETH J ROTHMAN

Department of Epidemiology and Biostatistics, Boston University School of Public Health, 715 Albany Street, Boston, MA 02118, USA

Susser M. Does risk factor epidemiology put epidemiology at risk? Peering into the future. 7 Epidemiol Community Health 1998;52:608-11.

2 Tesh S. Hidden arguments: political ideology and disease prevention policy. New Brunswick, NJ: Rutgers University Press, 1988.

3 Krieger N. Epidemiology and the web of causation: has anyone seen the spider? Soc Sci Med 1994;39:887-903.

der? $S o c$ Sci Med 1994;39:887-903.
Krieger N, Zierler S. What explains the public's health? A call for epidemioKrieger N, Zierler S. What explains the p
logic theory. Epidemiology 1996;7:107-9.

5 Shy C. The failure of academic epidemiology: witness for the prosecution. Am f Epidemiol 1997;145:479-84.

6 Vandenbroucke JP. Is "the causes of cancer" a miasma theory for the end of the twentieth century? Int $\mathcal{F}$ Epidemiol 1988;17:708-9.

Loomis D, Wing S. Is molecular epidemiology a germ theory for the end of the twentieth century? Int f Epidemiol 1990;19:1-3.

8 Pearce N, de SanJose S, Boffetta P, et al. Limitations of biomarkers of exposure in cancer epidemiology. Epidemiology 1995;6:190-4.

9 Wing S. Limits of epidemiology. Medicine and Global Survival 1994;1:7586.

10 Pearce N. Traditional epidemiology, modern epidemiology, and public health. Am f Public Health 1996;86:678-83.

1 Skrabanek P. The emptiness of the black box. Epidemiology 1994;5:553-5.

12 Savitz DA. In defense of black box epidemiology. Epidemiology 1994;5:550-

13 Savitz DA. The alternative to epidemiologic theory: whatever works. Epidemiology 1997;8:210-12.

14 Terris M. The epidemiologic tradition. Public Health Rep 1979;94:203-9.

15 Stallones RA. To advance epidemiology. Annu Rev Public Health 1980;1:6982.

16 MacMahon B, Pugh TF. Epidemiology: principles and methods. Boston: Little, Brown, 1970:23-5.

17 McKinlay JB. The promotion of health through planned sociopolitical change: challenges for research and policy. Soc Sci Med 1993;36:109-17.

\section{Multilevel ecoepidemiology and parsimony}

Mervyn Susser's paper is the most recent in an impressive series of papers on some of the conceptual issues lying at the intersection of epidemiology and public health. ${ }^{1-5}$ Building upon a historical account of the development of epidemiology, he argues that "chronic disease epidemiology" or "risk factor epidemiology" is (1) based on a "black box paradigm" in which exposures are related to health outcomes "without any necessary obligation to interpolate either intervening factors or even pathogenesis", and (2) committed "to analyse disease solely at the individual level" so that the societal context of exposure and health outcome is ignored. ${ }^{3}$ Combining the two arguments, he concludes that "risk factor epidemiology, in pure form, exploits neither the depth and precision of microlevels, nor the breadth and compass of macrolevels". ${ }^{5}$

Many contemporary epidemiologists will agree that epidemiological research should take disease mechanisms into account, not only in the interpretation of findings (to assess biological plausibility) but also by including into epidemiological studies measures representing the disease process (to increase precision of explanation). There is less evidence, however, for a similar willingness to take the "macrolevel" into account. Although this may partly be because of a lag-time between exposure of the epidemiological community to Susser's papers and the incidence of scientific publications reporting on studies inspired by his thinking, it is also probably because of a lack of understanding of the circumstances in which epidemiological studies would really benefit from combining variables representing the individual and the group level.

Many epidemiologists will agree that individual exposures and individual health are somehow shaped by the society these individuals live in, and may even refer to this societal context in the interpretation of their findings, on the basis of common sense or perhaps some cursory knowledge of the medical-sociological literature. But there is a big difference between such interpretative efforts and actually including in an epidemiological study direct measures of exposure and/or health at the group level. This could result in a study in which group level exposures, individual level exposures, and individual level health outcomes are related to each other, or a study in which individual level exposures, individual level health outcomes, and group level health outcomes are related to each other, or combinations of these. ${ }^{1}$ This is likely to be complicated, and goes against the epidemiologist's justified desire for parsimony. No single study can answer all questions, and effective study design requires that broad questions are partitioned into researchable bits and pieces. Why - the average epidemiologist is likely to ask-cannot epidemiology devote itself to studying individual exposures and individual health outcomes, and leave the study of group level influences on individual characteristics to other disciplines such as sociology? 
Susser's plea for "multilevel ecoepidemiology" will only convince the epidemiological community if it can be shown that combining individual level and group level variables in the study of exposure-health relations adds considerably to the knowledge that can be gained from separate studies of each of the relations involved. Although I sympathise with the plea, and see it as an intellectual challenge that may help to revitalise epidemiology's public health orientation, ${ }^{6}$ the evidence that there is indeed much to be gained still is limited to a few (important) areas. It is quite possible that this is simply the result of a lack of studies that have attempted to produce this evidence, but it should nevertheless warn us against overstating our claims.

The areas where the combination of individual level and group level variables in one study of exposure-health relations has been shown to have potential benefits are social epidemiology and infectious disease epidemiology. In social epidemiology, the interest is in the effect of social factors (socioeconomic status, social networks, ethnicity, etc) on health, and although the exposure to many of these social factors can be measured adequately at the individual level, there is at least some evidence that the social characteristics of groups have health effects that are not mediated by the corresponding characteristics of individuals. For example, in some studies living in a poor neighbourhood was shown to be associated with higher rates of ill health, even after controlling for individual income. ${ }^{78}$ Individual level studies of the relation between income and health will therefore lead to misleading results, which at the same time overestimate the effect of individual income on health, and underestimate the total effect of income (individual and neighbourhood level combined) on health. More fundamentally, certain social factors inherently are group attributes and can only be studied at the group level, using individual level characteristics to control for the effect of other influences. The frequently reported association between income inequality and mortality is a favourite example, ${ }^{910}$ but these were single level ecological studies in which no attempt was made to relate income inequality to individual mortality risks using individual income as a control variable.

In infectious disease epidemiology, the main benefit of combining individual and supra-individual variables in one study derives from the fact that the prevalence of an infectious disease in a population determines the individual risks of infection. ${ }^{11}$ If this group level variable is not entered into the equation, it will be impossible to estimate the effects of determinants of infectious disease occurrence in a valid way. While social epidemiology needs group level of exposures, infectious disease epidemiology needs group level measures of health outcomes (which will then act as additional measures of exposure).

Is it because of a lack of imagination or a narrowly individualistic focus of epidemiologists that no other areas have been explored? Perhaps, but it is also easy to see why social epidemiology and infectious disease epidemiology are the areas for which explorations have been made. In social epidemiology, the interest is in exposures that essentially concern relationships between individuals. In infectious disease epidemiology, the concern is with health outcomes that are defined in terms of their capability to spread from one individual to the other. It is probable that a further development of the concepts and methods of "multilevel ecoepidemiology" will benefit most from strengthening these two outposts first.

This implies a vast research agenda. For the sole area of social epidemiology, the issues to be tackled range from the conceptual (what are the relevant attributes of groups?) to the practical (how do we create data sets with sufficient level specific detail and power?) and from the theoretical (what is the appropriate unit of analysis?) to the methodological (how can lag-times between exposure and health effects be incorporated in the analysis, while at the same time allowing for changes over time in group membership?) It is Mervyn Susser's great merit that in his thought provoking papers he has helped in unlocking this new universe, which is both intellectually challenging and highly relevant for public health policy.

JOHAN P MACKENBACH Department of Public Health, Erasmus University Rotterdam, PO Box 1738, 3000 DR Rotterdam, the Netherlands

1 Susser M. The logic in ecological: I. The logic of analysis. Am f Public Health 1994;84:825-9.

2 Susser M. The logic in ecological: II. The logic of design. Am f Public Health 1994;84:830-5.

3 Susser M, Susser E. Choosing a future for epidemiology: I. Eras and paradigms. Am $\mathcal{F}$ Public Health 1996;86:668-73.

4 Susser M, Susser E. Choosing a future for epidemiology: II. From black box to Chinese boxes and eco- epidemiology. Am $\mathcal{F}$ Public Health 1996;86:674-7. 5 Susser M. Does risk factor epidemiology put epidemiology at risk? Peering into the future. I Epidemiol Community Health 1998;52:608-11.

6 Mackenbach JP. Public health epidemiology. 7 Epidemiol Community Health 1995;49:333-4.

7 Haan M, Kaplan GA, Camacho T. Poverty and health: prospective evidence from the Alameda County study. Am f Epidemiol 1987;125:989-98.

8 Humphries K, Carr-Hill R. Area variations in health outcomes: artefact or ecology. Int $\mathcal{F}$ Epidemiol 1991;20:251-8.

9 Wilkinson RG. Income distribution and life expectancy. BMF 1992;304: 165-8.

10 Kaplan GA, Pamuk ER, Lynch JW, et al. Inequality in income and mortality in the US: analysis of mortality and potential pathways. BMF 1996;3:9991003

11 Koopman JS, Longini IM. The ecological effects of individual exposures and non-linear disease dynamics in populations. Am f Public Health 1994; 84:836-42.

\section{The loss of the population approach puts epidemiology at risk}

Mervyn Susser correctly emphasises that our lack of understanding of social structures and social dynamics has led to major failures in identifying causes and preventing disease. ${ }^{1} \mathrm{He}$ also signals stagnation and scholasticism in mainstream, black box, epidemiological research. Scholasticism is certainly present, as certainly there is an inflation in the publication of results from epidemiological studies. Whether there is stagnation is debatable. So is the question whether the dynamism of new epidemiological subdisciplines (particularly molecular epidemiology) are a risk for epidemiology or whether they should rather be regarded as interesting newcomers.
Molecular biology has entered all domains of medicine. Whether we call this attrition or revolution is just a matter of timescale. After all, just a few decades separate the identification of the double helix from the polymerase chain reaction. Is oncology in danger because of the incorporation of new biological techniques to diagnose or treat patients? No, although some of the classic oncological approaches are, and for good reason. Is epidemiology in danger? No, although some of the classic epidemiological approaches are, and for good reason. The use of new powerful techniques to identify mechanisms and causes of disease, diagnostic tests or treatments can only be welcome. The incorporation of these techniques in epide- 
miological studies does not even affect the main epidemiological methods developed in the past 50 years. The real question is whether these techniques are incorporated in epidemiological studies or whether epidemiological studies are developed around the availability of these techniques. The latter is what occurred until now in many molecular epidemiology studies. Molecular biology seems still to be in a cross sectional phase, where the main task is the discovery of isolated components. In this phase the role of epidemiology is limited. The connection between these components, their function, their importance at population level and their interaction with external factors can be discerned as a coming phase where epidemiology will have much more to say.

One of the major successes of epidemiology has been its wide application in health research. Epidemiological studies examine the genetic predisposition to disease, the role of genetic polymorphisms, lifestyle factors, occupational and environmental exposures, socioeconomic factors, ergonomics, screening policies, chemoprevention, vaccine efficacy, or even the potential effects of global climatic changes, just to mention a few areas of research. They may refer to genetic alterations, any type of clinical or subclinical disease, to any age group, both sexes, to clusters of a few cases or to populations stretched around the world. The dispersion does not refer solely to different levels of causality (for example, molecular, individual, societal) but also to different medical or other health related specialties (for example, cardiovascular, psychiatric diseases, infectious diseases). All this is difficult to fit in the same basket. No health discipline can have such a wide area of research and aim, at the same time, to maintain its cohesion.

The danger for epidemiology, lies more in its increasing compartmentalisation within different clinical specialties rather than in the use of molecular techniques. The increasing interaction of epidemiologists with clinicians and basic scientists to identify the causes and mechanisms of disease is leading to a super-specialisation of epidemiology, similar to most other areas of health research. There are both positive and negative aspects in this. The close contact with basic scientists, clinicians, and other health professionals has helped them to standardise and improve the quality of their research. It has helped us, as epidemiologists, to develop more testable (plausible) hypotheses, to enter new areas of research, and to give serious attention to issues in which we had been slow to respond such as dementia, osteoporosis, restricted mobility, and social isolation. The negative aspect of super-specialisation lies in the potential loss of a comprehensive view of the causes and prevention of disease. The priorities for epidemiological research are increasingly defined on the basis of findings from clinical and laboratory studies, rather than on population-based evidence. Epidemiological studies should examine evidence from all levels of disease causation, molecular, individual, societal, global. Within this context, as Susser says, they should certainly pay more attention on social structures and dynamics. Rather than the black box approach, however, what seems to be a risk for epidemiology is the loss of the population approach that is central to epidemiological research.

This brings me to a last point made by Susser, that external forces drive major conceptual shifts. In most industrialised countries, the old welfare states implemented earlier this century are being dismantled by right wing, centre or centre-left governments, irrespectively. On a global scale, the World Bank, the G7, the tobacco industry, the food industries, and other multinationals are among the forces vying for control of the world's economies. The policies they apply pay little respect to human health. These policies also affect the type of research promoted, with less emphasis being put on population-based research. Are there any efficient counterparts to these forces within the public health sector? It is difficult to find them even in areas with active public health research, such as the European Union. Times do not seem to be ripe for population-based research and public health action. As pessimistic as this may seem, we should keep in mind that while epidemiological research depends on the society's priorities it may also contribute to redefine these priorities.

MANOLIS KOGEVINAS

Respiratory and Environmental Health Research Unit, Institut Municipal d'Investigació, Mèdica (IMIM), 80 Doctor Aiguader Road, Barcelona 08003, Spain

1 Susser M. Does risk factor epidemiology put epidemiology at risk? Peeering into the future. $\mathcal{F}$ Epidemiol Community Health 1998;52:608-11.

\section{Epidemiology between social and natural sciences*}

A rather intense debate has arisen in recent years concerning the essence and the role of epidemiology. ${ }^{1-5}$ Two extreme points of view seem to agree in claiming that "risk factor epidemiology" has reached a limit. The first point of view, more linked to the natural sciences and medicine, emphasises the potential developments of epidemiological research if the contribution of basic sciences (molecular epidemiology) is incorporated. The other view, closer to social sciences, insists that the vocation of epidemiology is to serve public health - that is, to identify the social determinants of disease at the population level, particularly poverty, material and cultural deprivation. Both agree in acknowledging the limitations of "risk factor epidemiology" - that is, an intermediate discipline that neither identifies genuine "causes" of diseases (because it does not tackle the biological bases adequately) nor contributes to the eradication of disease through the proper approach, which is a societal approach related to the living conditions of the people, stratified by social class.
I believe that the point against "risk factor epidemiology" is well taken, for both practical and theoretical reasons. From a theoretical point of view, we know that social inequalities and the structure of society are the ultimate determinants of the distribution of exposures and behaviours, so that sometimes it becomes almost impossible to disentangle the role of single risk factors. "Risk factor" epidemiology aims to be analytical, but it shows a limit in that separating, for example, the role of dietary habits from the role of several other exposures associated with social class may be a desperate attempt. From a practical point of view, to show in a very analytical way that innumerable attributes of lifestyle can be associated with the risk of disease, without modifying the underlying social mechanisms, looks rather sterile.

This debate is not new; what is new is the explosion, in recent years, of "risk factor epidemiology". However, great figures in the history of medicine, like Virchow, were able to reconcile the two roots of "social medicine". ${ }^{6}$ Virchow pio- 
neered the discovery of some basic mechanisms of disease-including the role of the cell-but in the mean time he solicited "social reforms" to improve the living conditions of the poor. He clearly perceived the different levels at which the study of disease must be conducted, from the subcellular to the social level. He also perceived that medicine must deal with each of these, respecting their specificity but striving for the creation of a bridge across them.

Epidemiology can be such a bridge. Epidemiological methods are at the roots of medical observation (experimental or non-experimental), and the originality of the discipline is just in its ranging from the strictly biological to the social domain. Rather than restricting the aims of epidemiology to the narrow view of risk factor epidemiology, we can consider our role in a much more attractive waythat is, as the discipline of "medical observation"-ranging from the molecular to the population domain.

Recent developments of epistemology emphasise that in biology we almost never face "universal laws". Probably the only universal law we deal with in biomedicine is the genetic code; otherwise, the type of laws we refer to are "middle range" theories. ${ }^{7}$ Middle range theories are described by Schaffner as "overlapping interlevel models", ${ }^{78}$ that is, they work in so far as they can explain biological events at different levels of reality, creating a bridge among such levels. This is true, for example, of the theory of evolution, which has been confirmed by observations ranging from population genetics to molecular biology. But it is true also of the bases of pharmacotherapy, where the evidence comes from studies in cell cultures, in animals, and in humans (randomised clinical trials). The limit of "risk factor epidemiology" is related to the fact the it does not make an effort to cross the boundaries, on one side towards the biological bases of observations in populations, on the other side towards social theories concerning the structure and stratification of society.

To mention an example, there is certainly a lot of good "risk factor epidemiology" (for example, based on questionaires and other traditional methods) still to conduct on the association between air pollution and cancer. The attacks that have been conducted against such studies are unjustified in so far as the qualitative level of the studies is acceptable, and sometimes excellent. However, we must recognise that in the absence of contributions from other levels, risk factor epidemiology in this field will, soon or later, reach a limit. We need to know the mechanisms that explain the carcinogenicity of air pollution at very low levels, but also to recognise that we are worried about air pollution partly because of the social inequality of its distribution. The latter aspect is both a methodological and an ethical problem. From a methodological point of view it has been claimed that the association between air pollution and lung cancer could be explained by confounders, such as occupational or dietary exposures (low intake of fruit and vegetable), which are related to social class. From the ethical point of view, the fact that exposure to a suspect agent of disease is unequally distributed in the population is itself a reason for concern. Thus, we cannot easily separate "risk factor epidemiology" from its biological premises on one side, and its social context on the other side. This problem is not new, as the integration between the "hermeneutic" component and the scientific basis has been described as the essence of medical practice. ${ }^{9}$

\section{PAOLO VINEIS}

University of Torino and Centre for Oncologic Prevention, via Santena 7, 10126 Torino, Italy

*I had written these notes before the editor invited me to comment upon Professor Susser's article. Therefore, I realised with a certain surprise that Susser had expressed-in a much more effective way-the same ideas I had conceived. This is a confirmation of Susser's intuition that a change in epidemiology is This is a confirmation of Susser's intuition that a change in epiden
mature, considering the diffuse concern for its goals and methods.

1 Krieger N. Epidemiology and the web of causation: has anyone seen the spider? Soc Sci Med 1994;39:887-903.

2 Susser M. Epidemiology today: a thought-tormented world. Int 7 Epidemiol 1989;18:481-8.

3 Pearce N. Traditional epidemiology, modern epidemiology and public health. Am f Public Health 1996;86:678-83.

4 Krieger N, Zierler S. What explains the public's health? A call for epidemiologic theory. Epidemiology 1996;7:107-9.

5 Susser M, Susser E. Choosing a future for epidemiology. I. Eras and paradigms. II. From black boxes to Chinese boxes. Am $\mathcal{F}$ Public Health 1996;86:668-73, 674-8.

6 Ackerknecht EH. Rudolf Virchow. Madison: The University of Wisconsin Press, 1953.

7 Schaffner KF. Discovery and explanation in biology and medicine. Chicago: University of Chicago Press, 1993.

8 Vineis P. Proof in observational medicine. 7 Epidemiol Community Health 1997;51:9-13.

9 Toulmin S. Knowledge and art in the practice of medicine: clinical judgment and historical reconstruction. In: Delkeskamp-Hayes C, Gardell Cutter MA. Science, technology, and the art of medicine. Dordrecht: Kluwer Academic, 1993.

\section{Epidemiology and bacteriology in 1900: who is the handmaid of whom?}

Susser's pledge for ecoepidemiology is timely and important. ${ }^{1}$ Recent developments in many disciplines offer epidemiologists the opportunity to simultaneously explore microlevel and macrolevel aspects of a given problem. It is a fascinating and stimulating perspective that I will try to incorporate in my work. I disagree, however, with the era categorisation proposed by Susser and more generally with the relevance of Kuhn's theory of dominant paradigms and scientific revolutions to legitimate the need for adapting epidemiological methods to these new scientific challenges.

As space is limited, I will focus my comment on one of the eras identified by Susser. I will try to show that there is very little or no historical evidence to support that "the scientific revolution that entrenched the Germ Theory" era in which epidemiology regressed and during which epidemiologists "rather than being the creative pace-setters of public health, served largely in the role of handmaidens applying the work of bacteriological colleagues". ${ }^{1}$

Imagine an epidemiologist in 1900 having to deal with an outbreak of diarrhoea and fever in a small village. The clinical presentation of the cases strongly evokes typhoid fever. This epidemiologist may be aware that a now famous bacteriologist has identified the microorganism that causes the disease. How helpful is this information to understand how the microorganism produced the outbreak, how contagion evolved, how to stop the outbreak, and how to prevent the next outbreak? Of very little help. Even if bacteriological analyses of stools are available, their sensitivity is low (many false negative) and there is no standard interpretation of the positive findings (for example, number of microorganisms, presence of Escherchia coli, etc). To answer the relevant questions for prevention, the 
epidemiologist will have to develop a strategy in which bacteriology plays little or no part at all.

Indeed, the turn of the century (largely 1880-1920) constitutes a period during which epidemiologists refined the methods for investigating an outbreak of acute infectious disease. They discovered, for example, that the agent of typhoid fever could be transmitted by salad, oyster or shellfish: in 1902, Timbrell Bulstrode, a local government board inspector, established that oysters were the cause of a food poisoning outbreak using the now familiar menu surveillance technique in which diners were asked to tick on a list the food items they had consumed. ${ }^{2}$ These methods are still taught and used today. "Bacteriology played little part in these assessments". ${ }^{2}$

Ann Hardy, an expert historian of English epidemiology, came to a conclusion that is diametrically opposed to that of Susser: "in the earlier investigations of typhoid (about 1890-1900), bacteriology featured occasionally as a handmaid to epidemiology". ${ }^{2}$ I cannot rule out that Susser's point is valid for Germany, where the germ theory may have resulted in a more bacteriological approach to disease outbreaks based on the investigation of the victim and the immediate contacts. But epidemiology at the turn of century was more developed in England than in Germany. In England the activity and historical contribution of epidemiologists to the understanding of the natural history of infectious diseases do not seem to have suffered from the impact of the germ theory in other fields of medicine.

Another important evolution that took place at the turn of the century is the birth of epidemiology as a profession. Before 1880, epidemiologists were essentially amateurs (general practicioners like Snow and Budd, military and naval physicians and surgeons). After 1880, professional epidemiologists were hired in England to practice epidemiology (for example, John Simon, William Frederick Barry, Theodore Thompson, H Timbrell Bulstrode, Edward Ballard, William G Savage). ${ }^{2}$ I suggest that this epoch of epidemiology has been previously neglected by epidemiologists rather than overshadowed and dominated by the germ theory.

Thus the activity of epidemiologists at the turn of the century cannot be explained by a Kuhnian paradigm shift. An alternative view is that epidemiology is a scientific discipline that has progressively emerged as a set of research methods, which have contributed to elucidating important questions related to human health. For about 150 years, epidemiologists have developed and refined the methods of outbreak investigations, the design of cohort and casecontrol studies, the concepts of confounding and interaction, the categorisations of types of bias, the process of causal inference. In this view, the history of epidemiology is characterised more by historical continuity and accumulation of methodological skills than ruptures related to changes of paradigms. Epidemiologists have emphasised different aspects of the methodology according to the exposures and diseases that were investigated.

Paradoxically, questioning the validity of the Kuhnian theory to interpret the history of epidemiology does not weaken the main message of Susser's paper: epidemiologists need to integrate the different levels of causality, from the molecular to the ecological one, to view all relevant levels as a whole. But what is the nature of the challenge? There is a wealth of indications that the integration of molecular biology into epidemiological research has become an irreversible process. The problem lies clearly in the macro-level, which Susser and Susser ${ }^{3}$ defined as the "causal pathways at the societal level". Is not Mervyn Susser calling our attention to the fact that contemporary epidemiologists have progressively overemphasised aetiological research for itself rather than for its public health implications. As a result, the individual levels and now cellular or molecular levels of causality have received more attention than the population level. This imbalance has been attributed by Pierce ${ }^{4}$ to the loss of the "population perspective". Even though I share this view, we must keep in mind that loss does not mean disappearance. For example, the mass strategy of prevention advocated by Geoffrey Rose $^{5}$ or the national programmes of surveillance of risk factors $^{6}$ are illustrations of a deep appreciation of epidemiological phenomena at the population level. But the methodological implications of this approach may not have been fully appreciated. ${ }^{7}$

In conclusion, I wholeheartedly welcome Susser's invitation to explore the methodological complexity of a multilevel epidemiology that lies ahead. On the other hand, I am not convinced that the history of epidemiology has been characterised by a paradigm struggle and I do not see the need of a new paradigm to ecoepidemiologise. In my view epidemiology has historically found its balance in the tension between the search for causal relations and the improvement of the public health. It is the overemphasis of any of these two components that puts epidemiology at risk.

ALFREDO MORABIA

Division of Clinical Epidemiology, 25 Rue Micheli-du-Crest, 1211

Geneva 14, Switzerland

Susser M. Does risk factor epidemiology put epidemiology at risk? Peeering into the future. F Epidemiol Community Health 1998;52:608-11.

Hardy A. Methods of outbreak investigation in the "era of bacteriology": 1880-1920. In: Morabia A, Fantini B, Bynum W, eds. History of epidemiologic concepts and methods. (In press).

3 Susser M, Susser E. Choosing a future for epidemiology: I. Era and paradigms. Am f Public Health 1996;86:668-73.

4 Pierce N. Traditional epidemiology, modern epidemiology and public health. Am F Public Health 1996;86:678-83.

5 Rose G. The strategy of preventive medicine. Oxford: Oxford University Press,

6 Morabia A. From surveillance of diseases to surveillance of risk factors. $\mathrm{Am}$ f Public Health 1996;86:625-7.

7 Morabia A, Beer-Borst S, Hereberg S for the EURALIM Study Group. Locally-based surveys, unite! The EURALIM example. Am f Public Health 1998;88:1153-6. 